\title{
A priori and a posteriori error analysis for a hybrid formulation of a prestressed shell model.
}

\author{
Serge Nicaise ${ }^{1}$, Ismail Merabet $^{2}$, and Rayhana REZZAG BARA ${ }^{2}$ \\ ${ }^{1}$ Universite Polytechnique Hauts-de-France \\ ${ }^{2}$ Kasdi Merbah Ouargla University
}

March 22, 2021

\begin{abstract}
This work deals with the finite element approximation of a prestressed shell model using a new formulation where the unknowns (the displacement and the rotation of fibers normal to the midsurface) are described in Cartesian and local covariant basis respectively. Due to the constraint involved in the definition of the functional space, a penalized version is then considered. We obtain a non robust a priori error estimate of this penalized formulation, but a robust one is obtained for its mixed formulation. Moreover, we present a reliable and efficient a posteriori error estimator of the penalized formulation. Numerical tests are included that confirmthe efficiency of our residual a posteriori estimator.
\end{abstract}

\section{Hosted file}

NMR_aposteriori.pdf available at https://authorea.com/users/403099/articles/514757-a-prioriand-a-posteriori-error-analysis-for-a-hybrid-formulation-of-a-prestressed-shell-model

\section{Hosted file}

NMR_aposteriori.tex available at https://authorea.com/users/403099/articles/514757-a-prioriand-a-posteriori-error-analysis-for-a-hybrid-formulation-of-a-prestressed-shell-model 


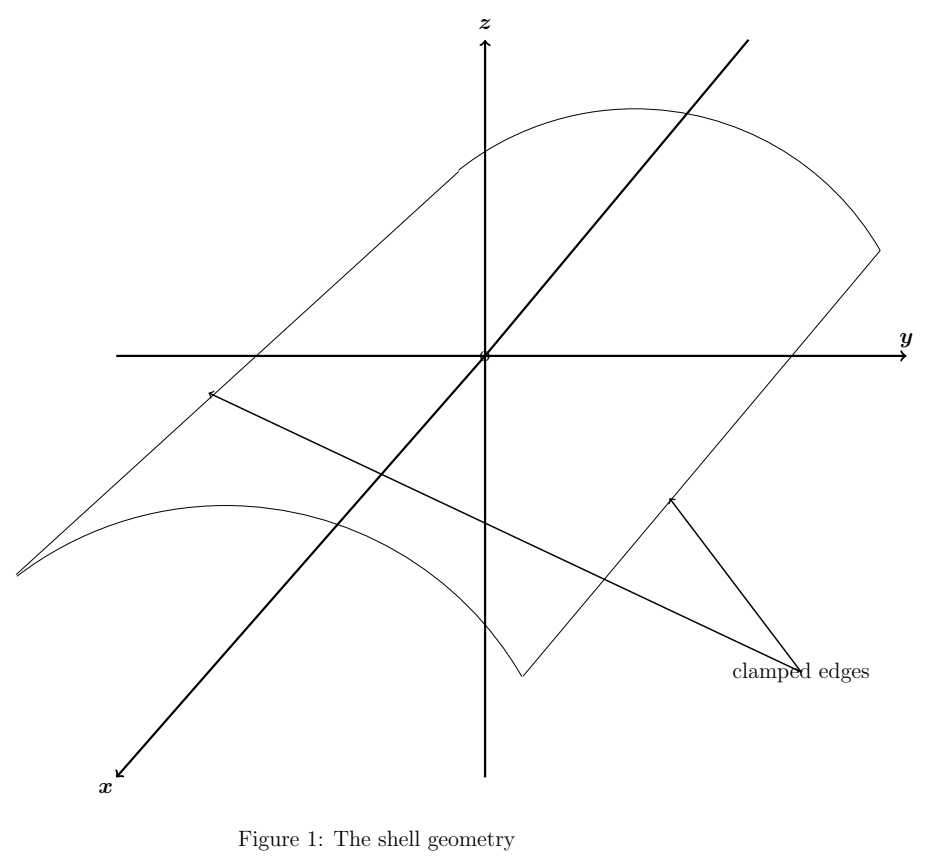



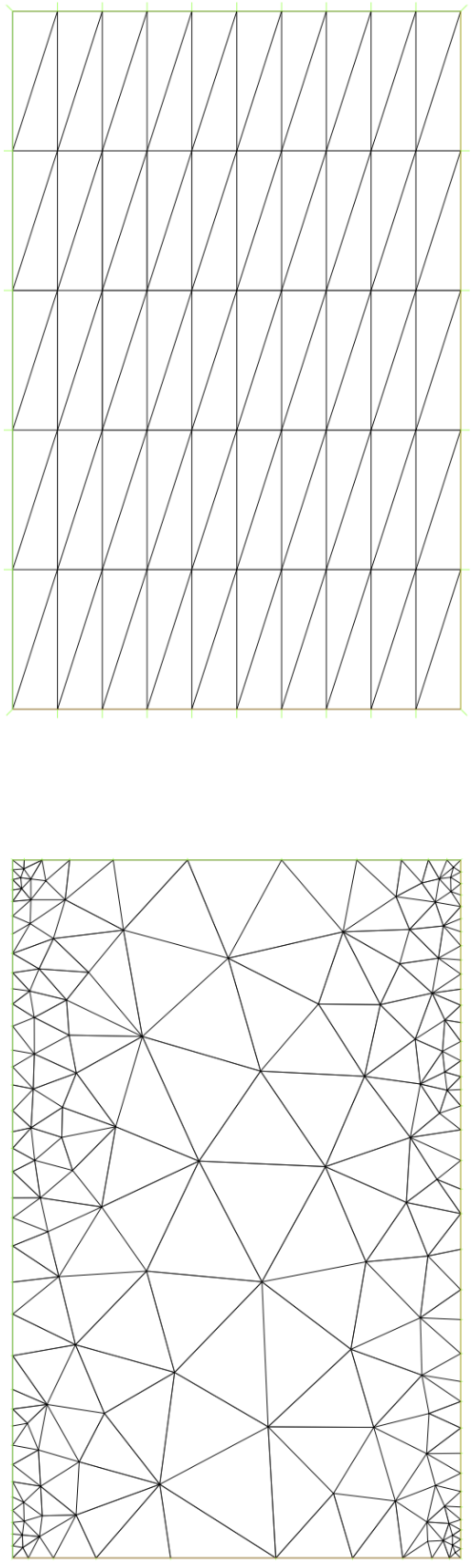


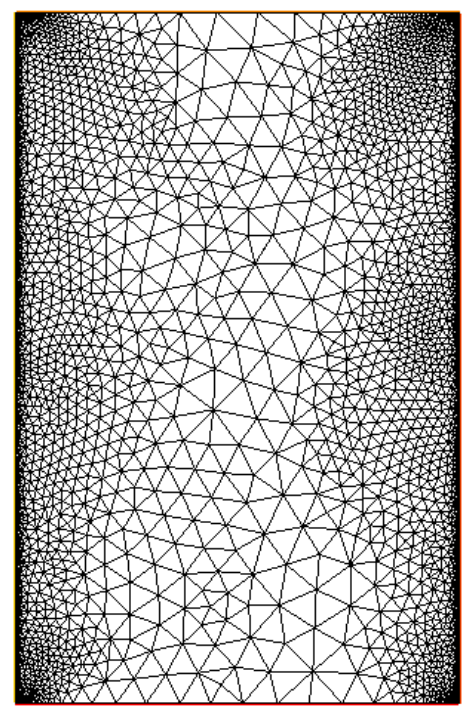

4 


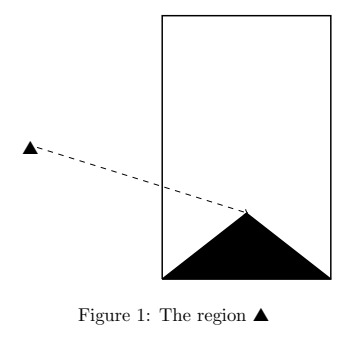

1

5 

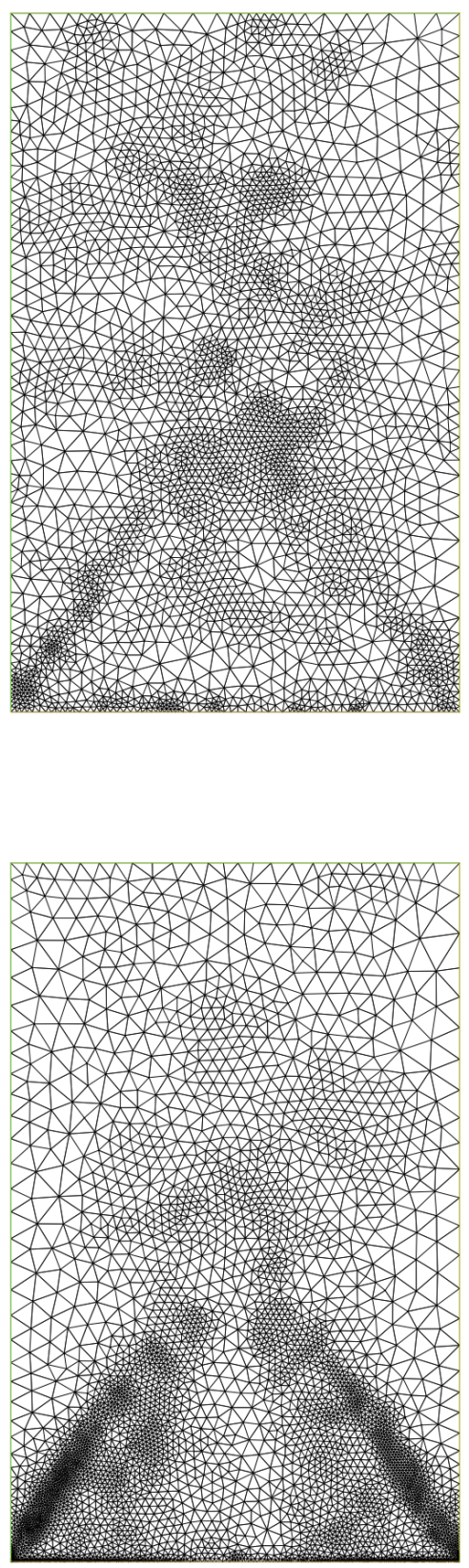